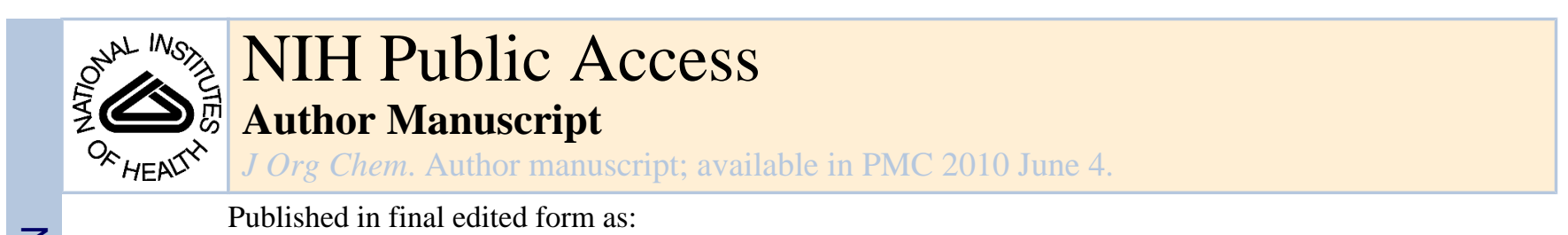

Published in final edited form as:

J Org Chem. 2009 March 6; 74(5): 2221-2223. doi:10.1021/jo802599v.

\title{
Synthesis of Deoxytetrahydrouridine
}

\author{
Jolanna Norton, Hiroshi Matsuo, and Shana J. Sturla \\ Department of Medicinal Chemistry, Department of Biochemistry, Molecular Biology, and \\ Biophysics, The Masonic Cancer Center. University of Minnesota, Minneapolis, MN 55455 \\ Shana J. Sturla: Sturl002@umn.edu
}

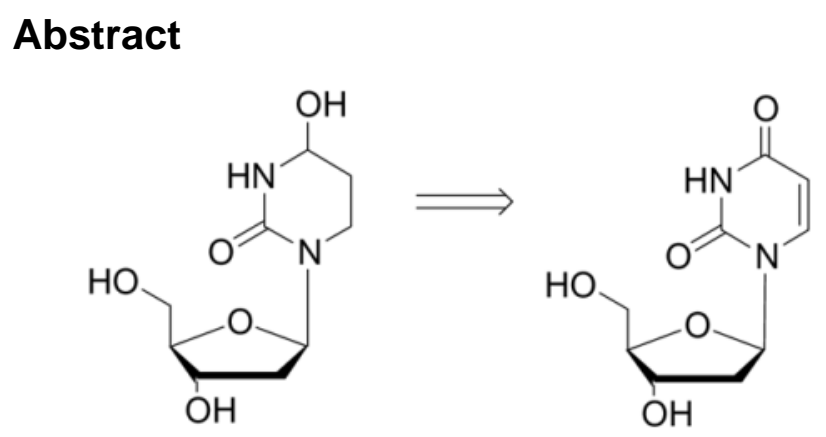

The $\alpha$-hydroxyamido functionality of 2'-deoxytetrahydrouridine (dTHU) makes this seemingly simple and generally useful compound difficult to obtain. Reported synthetic strategies produce extremely poor yields and multiple products, and full characterization data is not available. Described herein is a two-step approach for synthesizing dTHU in increased yields and purity; stability concerns are also addressed. Catalytic reduction (5\% Rh/alumina) of 2'-deoxyuridine, followed by reduction with sodium borohydride as a limiting reagent produces dTHU and limits formation of side products. Evidence was obtained for formation of a methoxy-substituted analog during purification. By this strategy, dTHU of $>95 \%$ purity can be obtained in $40 \%$ yield on a $150 \mathrm{mg}$ scale.

Reduced nucleoside analogs are of great interest as tools for understanding the chemistry and biology of nucleic acids, for probing proteins to which they bind, and for their medicinal properties. ${ }^{1-5}$ Tetrahydrouridines (THUs) and dihydrouridines (DHUs) (Figure 1) have been used in various studies, including as transition-state analogs of cytidine deaminase inhibitors (CDA). ${ }^{6,7}$ Our own interest in the deoxynucleoside of THU relates to ongoing studies of the human APOBEC $3 \mathrm{G}$ cytidine deaminase domain, which plays a defensive role in HIV infection. ${ }^{8,9}$ In studies of CDA substrate analog inhibitors, a tetrahedral transition state is proposed, such as that involving in situ generation of zebularine hydrate $\mathbf{2}$ from zebularine $\mathbf{1}$ (Scheme 1). ${ }^{10}$ Reduced pyrimidine analogs enabled the study of the hydrate as a discreet chemical entity. ${ }^{11}$ Thus, 3,4,5,6-tetrahydrouridine (THU) and the deoxy-analog dTHU have been subjects of research for over forty years. ${ }^{1,12}$ However, we were surprised to find that reported methods to prepare the compound are notably inefficient, and no diagnostic spectroscopic data are available in the literature. This report addresses a long-standing need for a reliable method to synthesize dTHU and provides its full chemical characterization.

Correspondence to: Shana J. Sturla, Stur1002@umn . edu.

SUPPORTING INFORMATION PARAGRAPH

${ }^{1} \mathrm{H}$ and ${ }^{13} \mathrm{C}$ NMR spectra and MS data for $\mathbf{6}$ and dTHU; ${ }^{1} \mathrm{H}$ NMR spectrum and MS data for 8 . This material is available free of charge via the Internet at http://pubs.acs.org. 
Photoreduction, catalytic hydrogenation, and borohydride reduction have been used to transform pyrimidine nucleosides to their hydropyrimidinone analogues. ${ }^{1,13}$ Typically referenced for the synthesis of dTHU is a 1967 study by Hanze and co-workers detailing the synthesis of THU. ${ }^{1}$ The procedure involves Rh/alumina-catalyzed hydrogenation of cytidine, to yield 3,4,5,6-tetrahydrocytidine. Acetic acid-mediated hydrolysis of this intermediate is reported to provide THU after multiple purification steps. While this general procedure can be used to synthesize the deoxy-analog dTHU from deoxycytidine (Scheme 2), in our experience, yields are poor $(<1 \%)$ for a $>95 \%$ purity sample of dTHU. The major drawback in application of Hanze's route is the difficult separation of dTHU from multiple impurities generated during the synthesis. Our experiences with dTHU preparation are consistent with Hanze's observations for the synthesis of THU. On the basis of MS and ${ }^{1} \mathrm{H}$ NMR analysis of the resulting mixture, major contaminants result from incomplete hydrogenation interrupted by hydrolysis (5), or over-reduction (6).

Hanze explored an alternative approach to synthesize THU by catalytic hydrogenation of uridine, followed by sodium borohydride reduction. ${ }^{1}$ However, this approach was abandoned due to even more severe complications due to impurities and the instability of the product to reaction conditions. Revisiting this strategy, we describe its success for the synthesis of dTHU on an approximately 150-mg scale, as illustrated in Scheme 3. The starting material dUrd is quantitatively converted to deoxydihdrouridine $\mathbf{6}$. The efficiency of the subsequent borohydride reduction of $\mathbf{6}$ to dTHU is extremely sensitive to reagent stoichiometry. With one equivalent of $\mathrm{NaBH}_{4}$, a significant amount of inseparable over-reduction side product 7 is produced, which results from a reaction pathway common in borohydride reduction of pyrimidines (Scheme 4). ${ }^{13}$ To circumvent this problem, $\mathrm{NaBH}_{4}$ is used with precise hydride equivalence, by combining it with four equivalents of $\mathbf{6}$. By carrying out the reaction with excess nucleoside, the only observed products are dTHU and remaining 6 , but no $\mathbf{7}$. Acidic quench of the crude borohydride reduction mixture, as described by Hanze, was eliminated to prevent acid-catalyzed hydrolysis of the dTHU 4-OH.

A further difficulty in the synthesis of pure dTHU is its instability. For example, storage of pure dTHU in basic methanol at $25^{\circ} \mathrm{C}$ for $12 \mathrm{~h}$ results in a mixture of dTHU and a new product with an $m / z$ of 269 and a ${ }^{1} \mathrm{H}$ NMR similar to dTHU containing a singlet at $3.33 \mathrm{ppm}$, consistent with the methanolysis product 8 (Scheme 5). Preparatory TLC was found to be the most reliable method of purification, reproducibly resulting in $>95 \%$ purity dTHU samples in consistent yields around $40 \%$ (based on 2'-deoxyuridine). Although certain factors, such as greater exposure to ambient oxygen, often make preparatory TLC an inferior method to column chromatography for purifying sensitive compounds, ${ }^{14}$ column chromatography on silica gel using a number of solvent combinations, including basic methanol, dichloromethane, and chloroform, was ineffective in this case. We speculated that silica surface area, acidity, or metal content are potential factors contributing to differences between these chromatographic techniques. ${ }^{15}$ Once purified, to prevent loss of dTHU to C4-hydrolysis or isomerization, samples were dried to a colorless film. ${ }^{1} \mathrm{H}$ NMR and MS analysis of dTHU samples stored at $-20^{\circ} \mathrm{C}$ in microcentrifuge tubes for four months showed no change in spectra.

In conclusion, we report a simple and reliable procedure for the synthesis of dTHU on an approximately $150-\mathrm{mg}$ scale reaction in $40 \%$ overall yield from dUrd. Although dTHU has been used in various studies over several decades, and is a fundamental pyrimidine modification, a reliable preparation and characterization data, to our knowledge, were not previously available. We anticipate that the approach described here, and the high purity product which can be obtained following this procedure will improve the quality of data obtained using dTHU as an experimental tool and will expand research in related areas. Furthermore, we expect that the spectroscopic data reported here will facilitate the identification of dTHU in complex mixtures. 


\section{EXPERIMENTAL SECTION}

For general methods and considerations, see Supporting Information.

\section{2'-deoxy-5,6-dihydrouridine (6)}

A suspension of 2'-deoxyuridine $(0.338 \mathrm{~g}, 1.48 \mathrm{mmol})$ and $5 \% \mathrm{Rh} /$ alumina catalyst $(0.125 \mathrm{~g}$, $0.06 \mathrm{mmol} \mathrm{Rh}$ ) in $15 \mathrm{~mL}$ water was placed on a Parr Shaker under hydrogen gas (45 psi) for 18 hours. The reaction solution was filtered through Celite to remove the Rh/alumina catalyst and concentrated under vacuum to afford pale yellow oil. TLC analysis indicated the formation of one product $\left(\mathrm{R}_{\mathrm{f}} 0.57\right)$. The oil was redissolved in $10 \mathrm{~mL} \mathrm{MeOH}$. Solvent was removed under vacuum to yield a white crystalline solid ( $341 \mathrm{mg}, 1.48 \mathrm{mmol}$, quantitative). ${ }^{1} \mathrm{H}$ NMR (300 $\left.\mathrm{MHz}, \mathrm{D}_{2} \mathrm{O}\right) \delta 2.05-2.13(\mathrm{~m}, 1 \mathrm{H}), 2.23-2.32(\mathrm{~m}, 1 \mathrm{H}), 2.70(\mathrm{t}, J=6.9 \mathrm{~Hz}, 2 \mathrm{H}), 3.47-3.54(\mathrm{~m}$, $2 \mathrm{H}), 3.62-3.76(\mathrm{~m}, 2 \mathrm{H}) 3.85-3.89(\mathrm{~m}, 1 \mathrm{H}), 4.31-4.36(\mathrm{~m}, 1 \mathrm{H}), 6.23(\mathrm{t}, J=7.2 \mathrm{~Hz}, 1 \mathrm{H}) ;{ }^{13} \mathrm{C}$ NMR $\left(\mathrm{D}_{2} \mathrm{O}\right) \delta 174.2,154.7,86.4,84.7,71.3,61.7,35.4,35.6,30.8$; MS (ESI+) $m / z 231(\mathrm{M}+$ $\left.\mathrm{H}^{+}\right), 253\left(\mathrm{M}+\mathrm{Na}^{+}\right)$.

\section{2'-deoxytetrahydrouridine (dTHU)}

A solution of 6 ( $341 \mathrm{mg}, 1.48 \mathrm{mmol})$ in water $(10 \mathrm{~mL})$ was cooled to $0{ }^{\circ} \mathrm{C}$. Sodium borohydride (14 mg, $0.4 \mathrm{mmol}$ ) was added to the cold solution. The reaction mixture stirred at $0{ }^{\circ} \mathrm{C}$ for 2 h. TLC analysis $\left(30 \% \mathrm{MeOH}-\mathrm{NH}_{3}: \mathrm{CHCl}_{3}\right)$ of the crude reaction mixture indicated the formation of two products $\left(\mathrm{R}_{\mathrm{f}} 0.68\right.$ and 0.44$)$. The reaction was removed from the ice bath and immediately placed under vacuum at room temperature. The resulting colorless oil was purified by preparatory TLC. Four spots were observed $\left(\mathrm{R}_{f} 0.75,0.64,0.55\right.$, and 0.22$)$. Isolation of the material with $\mathrm{R}_{f} 0.55$ yielded $143 \mathrm{mg}(0.6 \mathrm{mmol}, 41 \%$ yield) of the title compound as an oil. ${ }^{1} \mathrm{H}$ NMR (300 MHz, $\left.\mathrm{D}_{2} \mathrm{O}\right) \delta 1.65-1.90(\mathrm{~m}, 3 \mathrm{H}), 2.06-2.17(\mathrm{~m}, 1 \mathrm{H}), 3.15-3.25(\mathrm{~m}, 2 \mathrm{H})$, 3.44-3.63 (m, 2H) 3.63-3.70 (m, 1H), 4.12-4.18 (m, 1H), $4.87(\mathrm{t}, J=2.7 \mathrm{~Hz}, 1 \mathrm{H}) 4.91(\mathrm{t}, J=$ $2.7 \mathrm{~Hz}, 1 \mathrm{H}), 6.06-6.12(\mathrm{~m}, 1 \mathrm{H}) ;{ }^{13} \mathrm{C}$ NMR $\left(\mathrm{D}_{2} \mathrm{O}\right) \delta 156.4,84.8,84.3,72.3,71.2,61.9,35.3$, 33.9, 27.9; MS (ESI+) $m / z 217\left(\mathrm{M}^{+}-\mathrm{OH}\right), 233\left(\mathrm{M}+\mathrm{H}^{+}\right), 255\left(\mathrm{M}+\mathrm{Na}^{+}\right)$. HRMS $(\mathrm{m} / \mathrm{z}):[\mathrm{M}$ $+\mathrm{Na}^{+}$] calcd for $\mathrm{C}_{9} \mathrm{H}_{16} \mathrm{~N}_{2} \mathrm{NaO}_{5}, 255.0957$; found, 255.0953.

\section{Stability of dTHU in $\mathrm{MeOH}-\mathrm{NH}_{3}$}

dTHU (10 mg, $0.04 \mathrm{mmol})$ was dissolved in $1 \mathrm{~mL} \mathrm{MeOH}-\mathrm{NH}_{3}$. The resulting solution was stirred for 18 hours at $25^{\circ} \mathrm{C}$, then concentrated under vacuum to yield a clear oil. TLC analysis indicated the presence of dTHU $\left(\mathrm{R}_{\mathrm{f}} 0.58\right)$ and a new product $\left(\mathrm{R}_{\mathrm{f}} 0.58\right)$ Spectral data as follows is consistent with its structure being 4-methoxy-2'-deoxytetrahydrouridine (8). ${ }^{1} \mathrm{H}$ NMR (300 $\left.\mathrm{MHz}, \mathrm{D}_{2} \mathrm{O}\right) \delta 1.79-2.04(\mathrm{~m}, 3 \mathrm{H}), 2.20-2.31(\mathrm{~m}, 1 \mathrm{H}), 3.29-3.39(\mathrm{~m}, 5 \mathrm{H}), 3.58-3.73(\mathrm{~m}, 2 \mathrm{H})$ 3.77-3.84 (m, 1H), 4.28-4.32 (m, 1H), 5.04 (m, 1H), 6.23 (app. t, 1H); MS (ESI $\left.{ }^{+}\right) \mathrm{m} / \mathrm{z} 269$ (M $\left.+\mathrm{Na}^{+}\right), 217\left(\mathrm{M}+\mathrm{H}^{+}-\mathrm{OH}\right)$.

\section{Supplementary Material}

Refer to Web version on PubMed Central for supplementary material.

\section{Acknowledgments}

JAN acknowledges the University of Minnesota Graduate School for a DOVE Graduate Fellowship, the Department of Medicinal Chemistry for a Melendy Fellowship, and the National Cancer Institute for a Diversity Supplement (CA123007). Research was supported by the National Institute of Aging and Infectious Disease (AI073167). SJS is supported in part by an NCI Career Transition Award (CA108604). We are grateful to Heidi Dahlmann for editorial assistance. 


\section{References}

1. Hanze AR. J Am Chem Soc 1967;89:6720-6725. [PubMed: 6063658]

2. Marcus ET, Gundy A, Levenson CH, Meyer RB. J Med Chem 1988;31:1575-1579. [PubMed: 3165132]

3. Heinemann V, Plunkett W. Biochemical Pharmacology 1989;38:4115-4121. [PubMed: 2688654]

4. Aduma PJ, Gupta SV, De Clercq E. Antiviral Res 1990;13:111-125. 111. [PubMed: 2162147]

5. Aduma PJ, Gupta SV, Stuart AL, Tourigny G. Antiviral Res 1991;15:301-313. 301. [PubMed: 1659312]

6. Johansson E, Mejlhede N, Neuhard J, Larsen S. Biochemistry 2002;41:2563-2570. [PubMed: 11851403]

7. Johansson E, Neuhard J, Willemoes M, Larsen S. Biochemistry 2004;43:6020-6029. [PubMed: 15147186]

8. Sheehy AM, Gaddis NC, Choi JD, Malim MH. Nature 2002;418:646-650. [PubMed: 12167863]

9. Chen K, Harjes E, Gross PJ, Fahmy A, Lu Y, Shindo K, Harris RS, Matsuo H. Nature 2008;452:116119. [PubMed: 18288108]

10. Frick L, Mac Neela JP, Wolfenden R. Bioorg Chem 1987;15:100-108.

11. Frick L, Yang C, Marquez VE, Wolfenden RV. Biochemistry 1989;28:9423-9430. [PubMed: 2692708]

12. Maley F, Maley GF. Arch Biochem Biophys 1971;144:723-729. [PubMed: 4328164]

13. Balle G, Cerutti P, Bernhard W. J Amer Chem Soc 1966;88:3946-3950. 3946. [PubMed: 5915151]

14. Fried, B.; Sherma, J. Chromatographic Science. Vol. 81. Marcel Dekker, Inc; New York: 1999. ThinLayer Chromatography.

15. Nyiredy S, Dallenbach-Toelke K, Zogg GC, Sticher O. J Chromat 1990;499:453-462. 

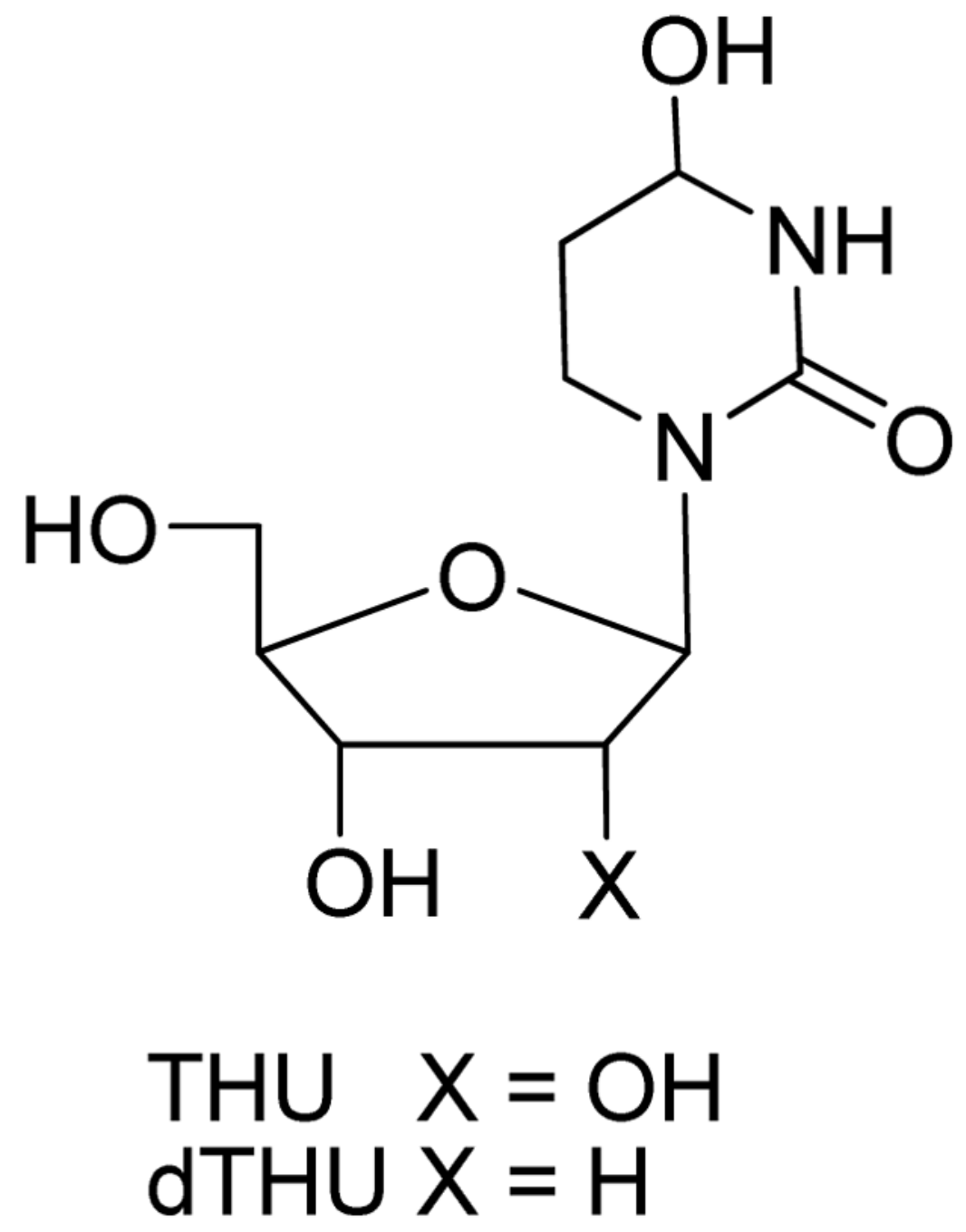

Figure 1.

Structure of tetrahydrouridine (THU) and deoxytetrahydrouridine (dTHU) 

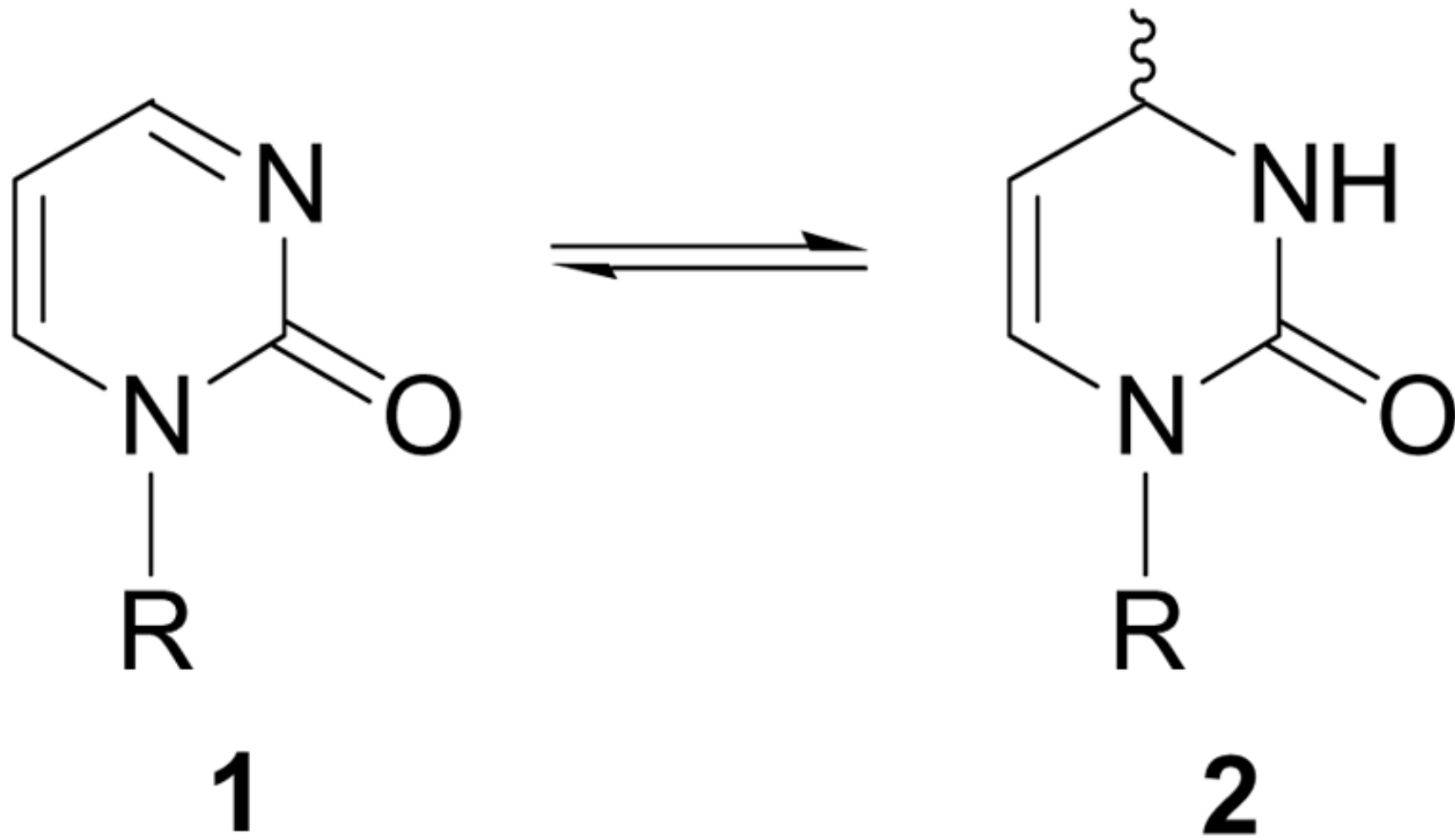

2

Scheme 1.

In situ hydration of zebularine $\mathbf{1}$. $\mathrm{R}=$ ribose. 
<smiles>NC1=NC(=O)N([Tl])CC1</smiles>
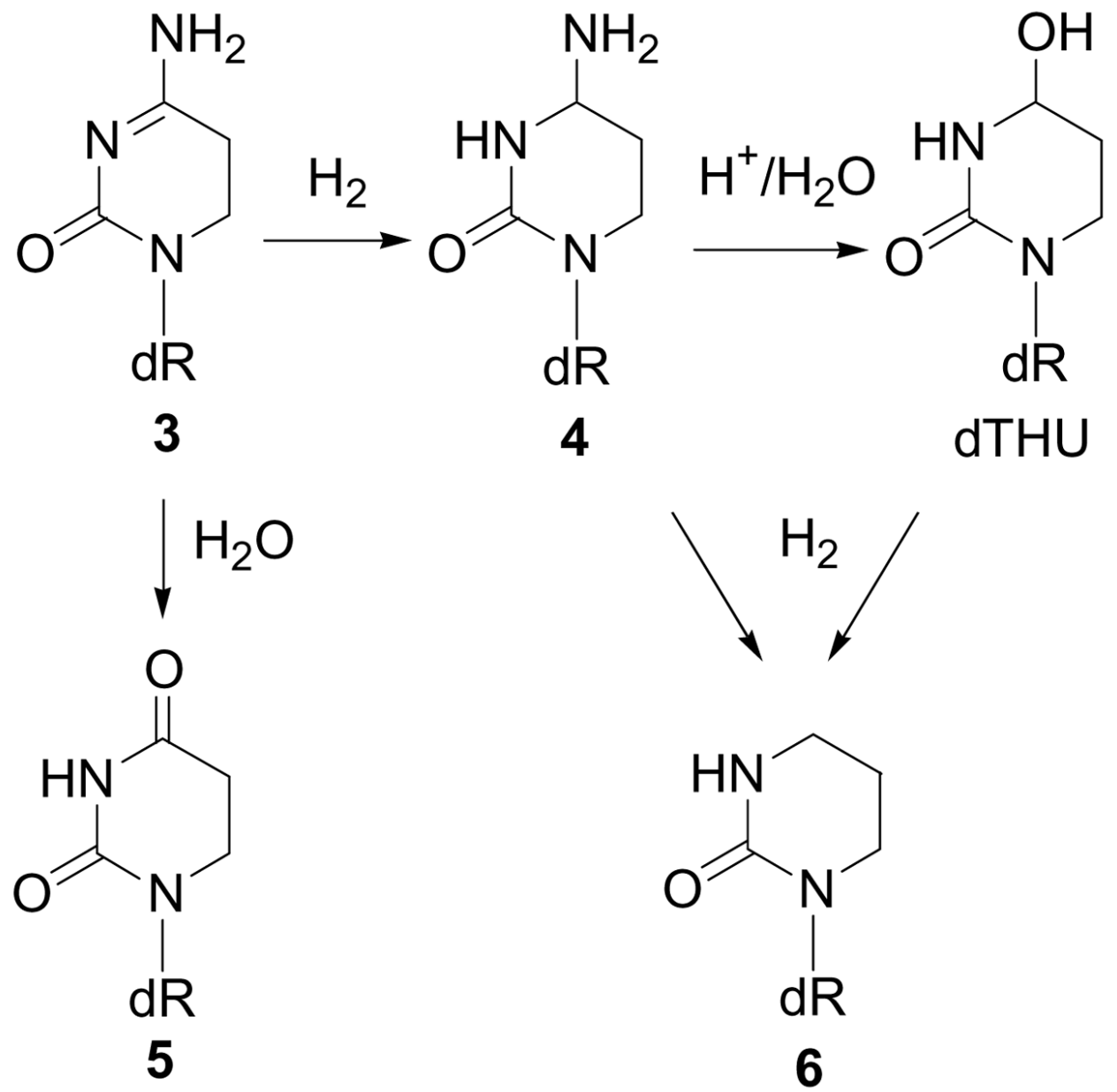

Scheme 2.

Synthesis of dTHU from dCyt, and competing undesired reactions. $\mathrm{dR}=$ deoxyribose. 


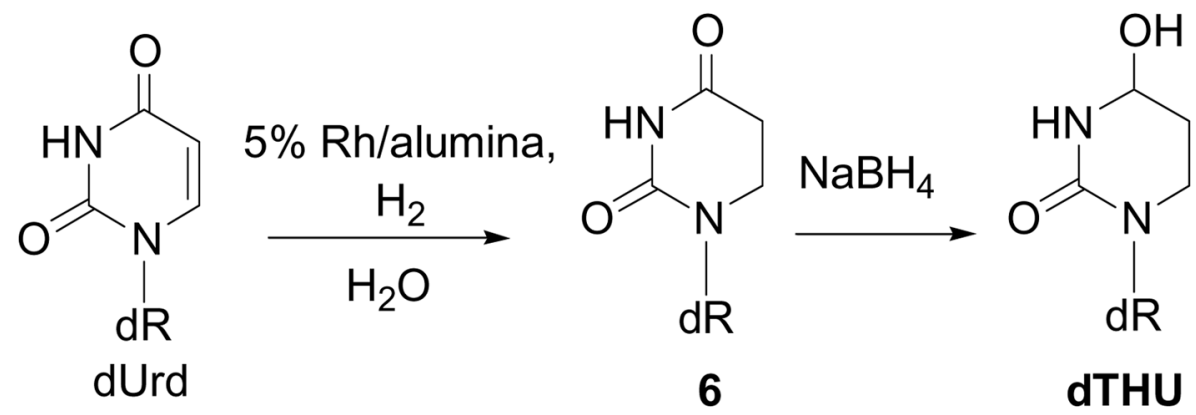

Scheme 3.

Synthesis of dTHU from dUrd. R=deoxyribose. 

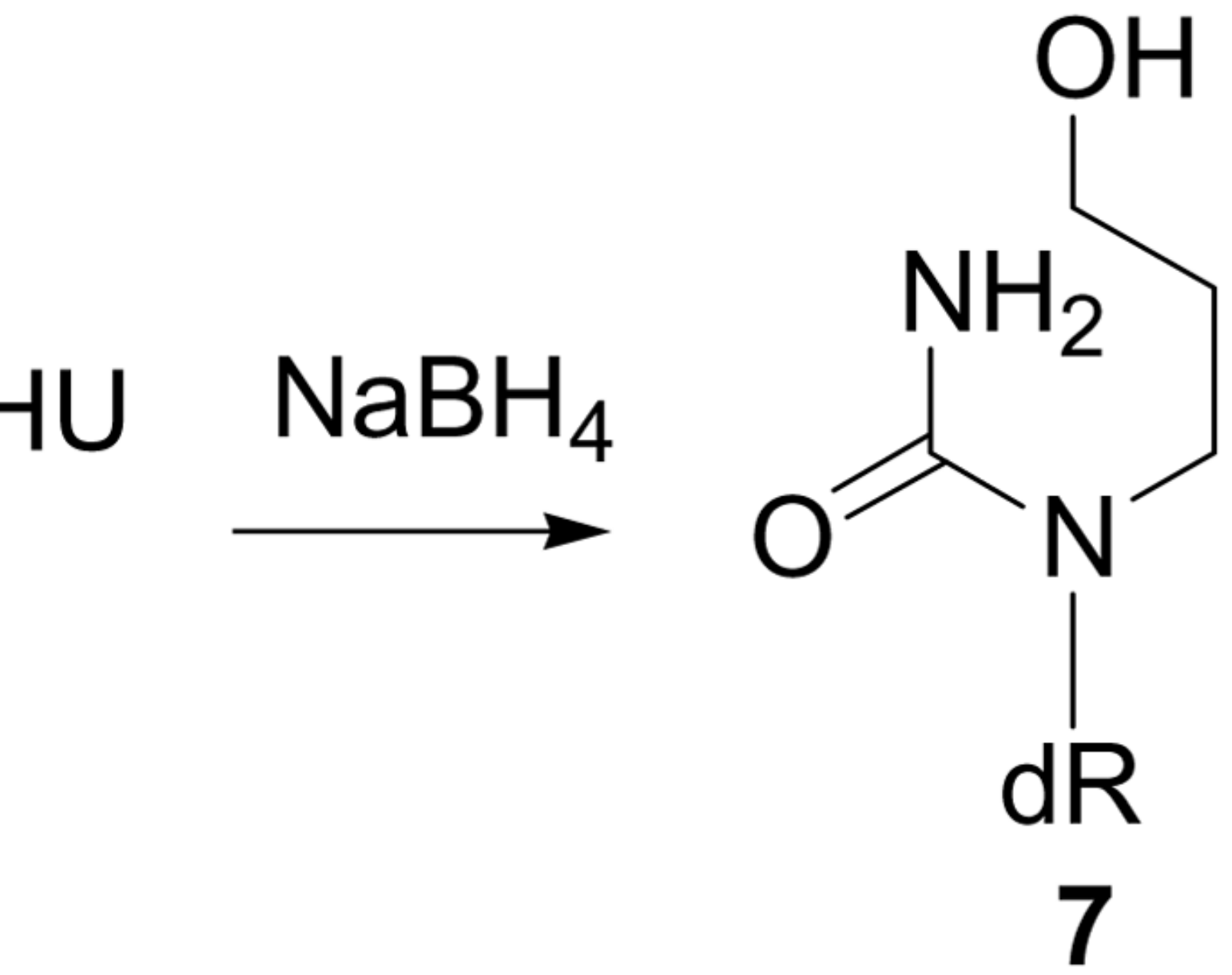

Scheme 4.

Over-reduction of dTHU is observed with if the reaction is carried out with one equivalent $\mathrm{NaBH}_{4}$. 


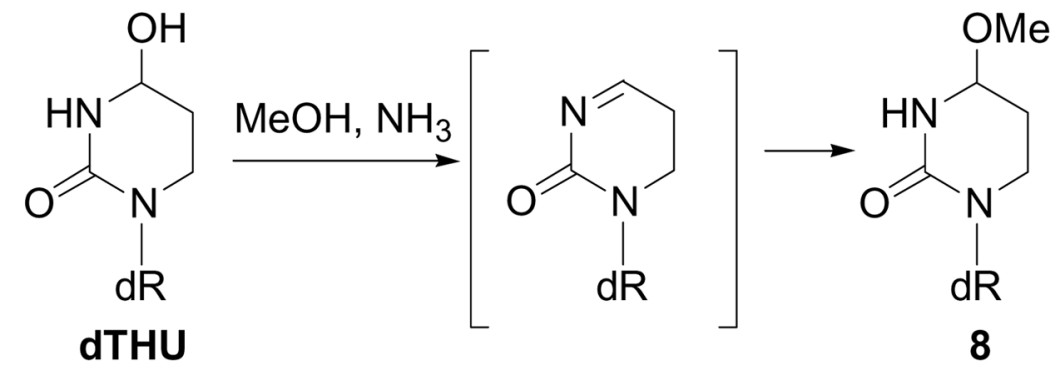

Scheme 5.

Methanolysis of dTHU. $\mathrm{dR}=$ deoxyribose. 